\title{
Antarctic Extremophiles: Biotechnological Alternative to Crop Productivity in Saline Soils
}

\author{
Ian S. Acuña-Rodríguez ${ }^{1}$, Hermann Hansen ${ }^{2}$, Jorge Gallardo-Cerda ${ }^{1}$, Cristian Atala ${ }^{3}$ and \\ Marco A. Molina-Montenegro ${ }^{1,4 *}$ \\ 'Center for Molecular and Functional Ecology (CEMFE), Instituto de Ciencias Biológicas, Universidad de Talca, Talca, Chile, \\ ${ }^{2}$ Facultad de Ciencias Agrarias, Universidad de Talca, Talca, Chile, ${ }^{3}$ Laboratorio de Anatomía y Ecología Funcional de \\ Plantas (AEF), Instituto de Biología, Pontificia Universidad Católica de Valparaíso, Valparaiso, Chile, ${ }^{4}$ Centro de Estudios \\ Avanzados en Zonas Áridas (CEAZA), Facultad de Ciencias del Mar, Universidad Católica del Norte, Coquimbo, Chile
}

\section{OPEN ACCESS}

Edited by:

Milko Alberto Jorquera, Universidad de La Frontera, Chile

Reviewed by:

Dirk Tischler,

Ruhr-Universität Bochum, Germany

Ashok K. Dubey,

Netaji Subhas Institute of Technology,

India

*Correspondence:

Marco A. Molina-Montenegro marco.molina@utalca.cl

Specialty section:

This article was submitted to Bioprocess Engineering,

a section of the journal Frontiers in Bioengineering and Biotechnology

Received: 18 October 2018 Accepted: 29 January 2019 Published: 19 February 2019

Citation:

Acuña-Rodríguez IS, Hansen $\mathrm{H}$ Gallardo-Cerda J, Atala C and Molina-Montenegro MA (2019)

Antarctic Extremophiles:

Biotechnological Alternative to Crop

Productivity in Saline Soils.

Front. Bioeng. Biotechnol. 7:22. doi: 10.3389/fbioe.2019.00022
Salinization of soils is one of the main sources of soil degradation worldwide, particularly in arid and semiarid ecosystems. High salinity results in osmotic stress and it can negatively impact plant grow and survival. Some plant species, however, can tolerate salinity by accumulating osmolytes like proline and maintaining low $\mathrm{Na}^{+}$concentrations inside the cells. Another mechanism of saline stress tolerance is the association with symbiotic microorganism, an alternative that can be used as a biotechnological tool in susceptible crops. From the immense diversity of plant symbionts, those found in extreme environments such as Antarctica seems to be the ones with most potential since they (and their host) evolved in harsh and stressful conditions. We evaluated the effect of the inoculation with a consortium of plant growth-promoting rhizobacteria (PGPB) and endosymbiotic fungi isolated from an Antarctic plant on saline stress tolerance in different crops. To test this we established 4 treatments: (i) uninoculated plants with no saline stress, (ii) uninoculated plants subjected to saline stress $(200 \mathrm{mM} \mathrm{NaCl})$, (iii) plants inoculated with the microorganism consortium with no saline stress, and (iv) inoculated plants subjected to saline stress. First, we assessed the effect of symbiont consortium on survival of four different crops (cayenne, lettuce, onion, and tomato) in order to obtain a more generalized response of this biological interaction. Second, in order to deeply the mechanisms involved in salt tolerance, in lettuce plants we measured the ecophysiological performance $\left(F_{\mathrm{v}} / F_{m}\right)$ and lipid peroxidation to estimate the impact of saline stress on plants. We also measured proline accumulation and $\mathrm{NHX} 1$ antiporter gene expression (involved in $\mathrm{Na}^{+}$detoxification) to search for possible mechanism of stress tolerance. Additionally, root, shoot, and total biomass was also obtained as an indicator of productivity. Overall, plants inoculated with microorganisms from Antarctica increased the fitness related traits in several crops. In fact, three of four crops selected to assess the general response increased its survival under salt conditions compared with those uninoculated plants. On the other hand, saline stress negatively impacted all measured trait, but inoculated plants were significantly less affected. In control osmotic conditions, there were no differences in proline accumulation and lipid peroxidation between inoculation treatments. Interestingly, even in control salinity, $F_{v} / F_{m}$ was higher in inoculated plants after 30 and 60 days. Under osmotic stress, $F_{v} / F_{m}$, 
proline accumulation and $\mathrm{NHX1}$ expression was significantly higher and lipid peroxidation lower in inoculated plants compared to uninoculated individuals. Moreover, inoculated plants exposed to saline stress had a similar final biomass (whole plant) compared to individuals under no stress. We conclude that Antarctic extremophiles can effectively reduce the physiological impact of saline stress in a salt-susceptible crops and also highlight extreme environments such as Antarctica as a key source of microorganism with high biotechnological potential.

Keywords: extremophiles, Antarctica, functional symbiosis, crops, food security, salt tolerance

\section{INTRODUCTION}

As a result of the global demand for processed food, intensive agricultural practices had altered the natural dynamics of the soil around the world, leading in many cases to the degradation of edaphic properties that are fundamental for crop productivity (Godfray et al., 2010). Rainfall and evapotranspiration dynamics, like those experienced by soils from arid and semiarid regions, could naturally produce a high concentration of diluted salts in the edaphic plant-rooting zone (Zhu, 2001; Zheng et al., 2009). However, several key aspects of intensive agricultural systems, like assisted irrigation, are actually one of the main drivers of soil saline accumulation (Allbed and Kumar, 2013). This process, known as soil salinization, represents one of the major forms of land degradation and was proposed to be a global problem for food security in the upcoming decades (Food and Agriculture Organization of the United Nations, 2009).

Today, agricultural productivity of arid and semiarid regions has become the most affected by salinity around the world (Rozema and Flowers, 2008), and traditional agricultural practices are already being challenged to maintain crop productivity. The pressure on agricultural soils will likely increase at a global scale in the future. This mainly due to the increased food demand as the world's population increases (Godfray et al., 2010), and the expected restrictions in water use as predicted by climate change models. Thus, alternative practices that allow the utilization of degraded soils for crop production could became necessary in the near future. One of these practices, plantmicrobe symbiosis, is highlighted as one of the most promising tools in such context (Paul and Lade, 2014; Joshi et al., 2015). For this reason, the mechanistic analysis of this kind of interactions, and their evaluation for crop production, must be of primary interest in the upcoming years.

Whereas a consequence of low osmotic potential (Munns and James, 2003), specific saline ion stress (Tester and Davenport, 2003) or nutritional imbalances derived from saline edaphic accumulation (Ashraf and Harris, 2004), salinity on soils can cause strong adverse effects on plant growth and development in several crop species (Glenn et al., 1999). Nevertheless, plants have developed a wide variety of mechanisms to cope with high saline concentrations in the environment (Munns, 1993; Forni et al., 2017). For example, at the cellular scale, the accumulation of organic osmolytes (e.g., proline, glycine, betaine, sugar alcohols, or polyamines), play a key role in preventing the harmful effects of salinity stress by maintaining a low intracellular osmotic potential (Pandey et al., 2015; Reddy et al., 2015; Saha et al., 2015). This was clearly demonstrated in the Arabidopsis thaliana knockout variety P5CS1, which fails to encode $\Delta-1$ pyrroline-5-carboxylate synthetase, impairing proline synthesis, which resulted in a salt hypersensitive plant (Székely et al., 2008; Szabados and Savoure, 2010). Other mechanisms of saline-stress control are related to the maintenance of low cytoplasmic $\mathrm{Na}^{+}$ concentrations. This could be achieved by the augmentation of the tonoplast-localized $\mathrm{Na}^{+} / \mathrm{H}^{+}$exchanger protein $\mathrm{NHX1}$, which detoxifies the cells via sequestration of $\mathrm{Na}^{+}$cations within the vacuole (Sun et al., 2017). In this sense, strategies at the genetic scale, as the constitutive over-expression of the AtNHX1 gene have shown increases on plant tolerance to salinity in Arabidopsis sp., but also in important crops like tomato and rice (Assaha et al., 2017; Sun et al., 2017).

Despite significant efforts (Munns and Tester, 2008; Dodd and Pérez-Alfocea, 2012; Coleman-Derr and Tringe, 2014; Krishna et al., 2015), traditional breeding and genetic engineering approaches have had only limited successes in developing salinity-resistant plants. However, the utilization of microbial symbionts has arisen as a successful (and relatively simple) biotechnological tool to achieve this goal (Bianco and Defez, 2009; Karlidag et al., 2013; Kang et al., 2014; Radhakrishnan et al., 2015; Forni et al., 2017). In fact, due to their active role in the regulation of a wide variety of plant physiological responses, the inoculation of specific microbial species on different plant hosts has been linked to enhance stress-tolerance responses against both biotic and abiotic factors (Cocking, 2003; Redman et al., 2011; Kang et al., 2015; Rho et al., 2017). However, despite the wide diversity of microbial symbionts that are present on almost all plant species; those associated with plant hosts from extreme environments appear to be the most promising in developing biological alternatives to assist crop production (Molina-Montenegro et al., 2016; Orhan, 2016; Qin et al., 2016). This could be consequence, at least in part, of the adaptive nature supposed for asymptomatic plant-microbe interaction in extreme environments (Saikkonen et al., 1998); but also because the selective pressure that these kinds of ecosystems imposes on plants demands specific biological responses, in this case, via symbiotic interactions (Redman et al., 2011).

Consequently, the Antarctic terrestrial ecosystem appears as a promising place to find plant-associated microorganisms that could confer plants protection against abiotic stress (Upson et al., 2009; Santiago et al., 2017; Gallardo-Cerda et al., 2018; Ramos et al., 2018). Besides its isolation, Antarctica is characterized 
by harsh environmental conditions like low temperatures, low water content, low nutrient availability and saline soils (Convey et al., 2008; Gallardo-Cerda et al., 2018). In such conditions, only two native vascular plants grow: Colobanthus quitensis and Deschampsia antarctica (Alberdi et al., 2002). In the last 10 years, the interest in microorganisms associated to these vascular plants has greatly increased, finding promising bacterial and fungal strains with a wide spectrum of applications (Parnikoza et al., 2011; Fardella et al., 2014; Molina-Montenegro et al., 2016; Santiago et al., 2017).

Related to the saline stress tolerance, the microbial symbionts of both Antarctic vascular plant species appeared as great candidates to explore this role, since at the local scale these plants can be found primarily along the ice-free zones close to the coast, where their populations are constantly subjected to saline spray influence (Convey et al., 2008). For example, Gallardo-Cerda et al. (2018) showed the beneficial effect of various Antarctic rhizospheric bacteria (e.g., Arthrobacter sp.) in the physiology and survival of both native plants under controlled conditions of salt stress $(200 \mathrm{mM}$ of $\mathrm{NaCl})$. Similarly, Torres-Díaz et al. (2016) found a strong functional role of the microbial symbionts of $C$. quitensis, particularly its rootfungal endophytes, in the ecophysiological improvement of plant individuals under osmotic stress. Interestingly, some of these Antarctic microorganisms (i.e., root-fungal endophytes and halotolerant rhizobacteria) have also shown the potential to improve the physiological performance of non-native host plants (Fardella et al., 2014), which could be quite important for a future use as biotechnological tool. Nevertheless, beyond the positive effects observed in some crops as a consequence of a manipulative symbiosis, there is still a lack of understanding regarding the mechanisms behind these positive effects under stressful conditions. For example, for most crop-microbial symbiosis, it is not clear if the observed benefits are a direct consequence of counteracting specific abiotic stressors (i.e., increased tolerance; Kim et al., 2014; López-Gómez et al., 2014), or an indirect effect derived, for example, from an enhanced nutritional status (Upson et al., 2009; Dodd and Pérez-Alfocea, 2012). On the other hand, some studies have been conducted to test the effect of microorganisms associated to Antarctic plants on stress tolerance in others plants, but all of them have been addressed using only an specific functional group (i.e., rhizobacteria or fungal), but neither has assessed the "consortium." This is surprising, because in a realistic scenario these functional groups are interacting in a determined way, exerting an inhibitory, neutral or synergic effect among then. In fact, the effect of isolated specific functional group can exert a different effect compared when is considered as part of the microbiome (Vandenkoornhuyse et al., 2015). In this sense, to determine the biotechnological potential of a given crop-microbe functional symbiosis against a particular stressor like saline soils, it is important to identify which response mechanisms are triggered in the host plant as a consequence of the microbial presence as well as to determinate the effects of functional groups acting as part of the microbiome of a given plant species rather than as isolated symbionts.

Hence, to evaluate the potential of a selected group of Antarctic extremophiles to ameliorate the stressful effect of soil salinization on susceptible crops, we monitored the physiological (individual) and biochemical (cellular) performances of inoculated and non-inoculated lettuce plants exposed for 60 days to saline stress. Furthermore, to determine the potential mechanisms involved in the observed stress-response enhancement, we analyzed the foliar accumulation of proline and the relative expression of saline-stress related genes like NHX1. Finally, we established the overall effect of the interaction between saline stress and symbiosis on the final biomass of lettuce individuals as an indicator of crop productivity.

\section{MATERIALS AND METHODS}

\section{Generation of the Symbiont Consortium}

The consortium of microorganisms used in our study was composed by two halotolerant plant growth-promoting rhizobacteria (PGPR) of the genus Arthrobacter sp. and Planoccocus sp. and two root-fungal endophytes; identifies as Penicillium chrysogenum and Penicillium brevicompactum. In brief, both rhizobacteria used for this study were selected because are one of the most abundant in the rhizosphere of antarctic plants, ease to cultivate and has been demonstrated to growth under high salt concentrations (Gallardo-Cerda et al., 2018). In addition, these rhizobacteria has been showed to improve the ecophysiological performance of their native hosts in Antarctica (Gallardo-Cerda et al., 2018). On the other hand, root fungal endophytes selected to use in this study were selected because are the two most abundant in the root of Antarctic plants and can be grown at different temperatures and abiotic conditions in the laboratory (Molina-Montenegro et al., 2016). In addition, these endophytes have been demonstrated to improve the ecophysiological performance and productivity in crops under osmotic stress (Molina-Montenegro et al., 2016). Both rhizobacteria and fungal endophytes were identifies and its sequences deposited in the gene-bank. These inoculums are maintained as part of the collection of microorganisms of the Plant Ecology Laboratory, Universidad de Talca, Chile. The inoculums were separated in different Petri dishes and then frozen until to be used in the experiments.

For more details of isolation, inoculation, and the gene-bank code (see Molina-Montenegro et al., 2016; Gallardo-Cerda et al., 2018).

Plant inoculation was performed according to the procedure describe by Hadi et al. (2010) with the selected consortium of microorganisms. Briefly, the rhizosphere of each crop individual was injected with $\sim 2 \mathrm{ml}$ of distilled water containing a concentrated mix of spores $\left(5,000\right.$ spores $\left.\mathrm{ml}^{-1}\right)$ from each fungal endophyte, and about $10^{8}$ cells $\mathrm{ml}^{-1}$ of the bacterial species. A posterior validation of the effectiveness of the inoculation was conducted using a light microscope in a subsample of roots ( $10 \%$ of the experimental individuals) 1 week after inoculation, and at the end of the experiment (60 days).

Fresh inoculums were obtained during March 2017 from single-conidia of fungal endophytes cultured on potato dextrose agar (PDA) medium diluted eight times and supplemented with $50 \mathrm{mg} / \mathrm{ml}$ of streptomycin. Cultures with endophytes were incubated at $22 \pm 2^{\circ} \mathrm{C}$ with a photoperiod 14/10 day/night. 
After 2 weeks of incubation, conidia were harvested from plates by adding $10 \mathrm{ml}$ of sterile water and gently scraping off conidia with a sterile glass slide. The conidia suspension was adjusted to $100 \mathrm{ml}$ of $0.05 \%$ Tween-100, sterilized solution, filtered through three layers of sterile cotton cheesecloth gauze. Conidia concentration was estimated by using a Neubauer chamber and adjusted to $1 \times 10^{5}$ conidia/ml and its viability was tested according to methodology described by Greenfield et al. (2016) and the mean conidia viability was $>95 \%$. In addition, rhizobacteria used in this assays were cultured in Laura Bertani broth (LB). Later, they were mixed on an orbital shaker with a speed of $120 \mathrm{rpm}$ and incubated at $10^{\circ} \mathrm{C}$ for $72 \mathrm{~h}$. The incubated broth cultures were then centrifuged for $15 \mathrm{~min}$ at 3,000 rpm. Pelleted cells were suspended in sterile distilled water and its optical density was adjusted to about $10^{8}$ cells $^{*} \mathrm{ml}^{-1}$. Symbiont consortium (fungal endophytes + rhizobacteria) was injected in the rhizosphere, according the procedure describe by Hadi et al. (2010).

\section{Overall Assessment of Symbiont Consortium in Crops}

To test the overall effect of symbiont consortium on salt tolerance in crops, we compared the survival percentage of individuals of cayenne (Capsicum annuum), lettuce (Lactuca sativa), onion (Allium cepa), and tomato (Solanum lycopersicum) inoculated and un-inoculated with microorganisms as well as exposed to salt-stressed and control condition. The plant inoculation was repeated two times to ensure the consortium to establish an effective association. Before the beginning of the experiment, three plants of each species/treatment were sacrificed to check microscopically for the presence and/or absence of microorganisms by routine staining of roots.

Seedlings of these crop species were obtained from seeds germinated in glasshouse located at the Universidad de Talca, Talca, Chile $\left(35.4^{\circ} \mathrm{S}\right)$, under semi-controlled environmental conditions of light and temperature $\left(730 \pm 77 \mu \mathrm{mol} \mathrm{m}^{-2} \mathrm{~s}^{-1} ; 23\right.$ $\pm 5^{\circ} \mathrm{C}$, respectively). For treatment setup, crop seedlings were transplanted into the field when individuals presented at least four expanded leaves and/or 3-cm roots. One-hundred seedlings of each species were randomly assigned to one of the following treatments: (i) Saline stress: control individuals watered without salt addition, and stressed individuals watered with a $0.2 \mathrm{M}$ saline water solution; (ii) Symbiont inoculation: control plants (S-) without the set of Antarctic extremophile microorganisms, and infected plants $(\mathrm{S}+)$ which were inoculated with the symbiont consortium described above. Thus, the four treatments corresponded to S+ plants with and without salt stress and Splants with and without salt stress, with a sample size of 25 plants per treatment per crop species (total $n=400$ individuals). Finally, each group of 25 individuals was grouped in five group with five individuals each one. Survival percentage was recorded at 60 days on each group of five seedlings per treatment in the field.

\section{Experimental Arrangement to Evaluate Salt Tolerance in Crops}

We decided to use lettuce as a model crop to deeply the understanding about mechanisms and consequences of microorganisms to confer environmental tolerance in crops.
This crop has been shown to be highly sensitive and dependent on water at all developmental stages (Sánchez, 2000; MolinaMontenegro et al., 2011), and demands constant watering to maintain high photosynthetic rates and a fresh biomass of high commercial value (Nissen and San martín, 2004). Complementarily, lettuce has also shown the ability to accept non-native microbial symbionts and moreover, to respond positively to these new partners (Molina-Montenegro et al., 2016). Consequently, during April 2017, 500 lettuce seeds (var. Romaine) were germinated in greenhouse conditions. After 3 weeks, 125 seedlings were transplanted to individual pots containing $500 \mathrm{ml}$ of a peat: perlite: sand mix (35\%: 35\%: 30\%) as substrate. Their successful establishment was verified for 1 more week previous to any experimental treatment.

From the set of 114 successfully established seedlings, 100 individuals were selected for the experiments and were then randomly divided into four groups of 25 to fulfill the factorial combination of the two experimental variables of saline stress and effective symbiosis $(2 \times 2$ full factorial design $)$. The respective treatments were (i) Saline stress: control individuals watered without salt addition, and stressed individuals watered with a $0.2 \mathrm{M}$ saline water solution; (ii) Symbiont inoculation: control plants (S-) without the set of Antarctic extremophile microorganisms, and infected plants $(\mathrm{S}+)$ which were inoculated with the symbiont consortium. Thus, the four treatments corresponded to S+ plants with and without salt stress and Splants with and without salt stress, with a sample size of 25 plants per treatment. The referred consortium of microorganisms was the same to those used to assess the overall effect on survival of several crops indicated above. Similarly, a posterior validation of the effectiveness of the inoculation was conducted using a light microscope in a subsample of roots $(10 \%$ of the experimental individuals) 1 week after inoculation, and at the end of the experiment (60 days).

\section{Estimation of the Saline Stress Effect}

Having validated the symbiosis by re-inoculation and visual assessment in root samples of experimental plants, half of the 4-weeks old inoculated seedlings, started their saline-stress treatment included in the watering routine. We estimated the photochemical efficiency and the membrane lipid peroxidation state as two physiological/biochemical proxies of osmotic stress (Egert and Tevini, 2002; Molina-Montenegro et al., 2013). To measure chlorophyll fluorescence we obtain the minimum $\left(F_{0}\right)$ and maximum $\left(F_{\mathrm{m}}\right)$ fluorescence yields per individual $(n=10)$ using a pulse modulated-amplitude fluorimeter (FMS 2, Hansatech, Instrument Ltd, and Norfolk, UK). The baseline $\left(t_{0}\right)$ measurements were taken previous to the saline addition and were also estimated after 30 $\left(t_{30}\right)$ and $60\left(t_{60}\right)$ days. In each case we calculated the maximum quantum yield of photosystem-II $\left(F_{\mathrm{v}} / F_{\mathrm{m}}\right)$, where $F_{\mathrm{V}}$ refers to $F_{0}-F_{\mathrm{m}}$ (Maxwell and Johnson, 2000). To ensure maximum photochemical efficiency, the chosen leaves from each individual were dark-adapted for $30 \mathrm{~min}$ previous to the measurements.

Complementary to the individual level of response denoted by the photochemical efficiency, we estimated the state of 
lipid oxidative degradation by the thiobarbituric acid reactive substances (TBARS) assay (Egert and Tevini, 2002), which measures the concentration of malondialdehyde (MDA) at the cellular level as a proxy of cell damage. For each experimental group, the lipid peroxidation state in $0.5 \mathrm{~g}$ of fresh foliar tissue samples from five random individuals was estimated at each time (i.e., $t_{0}, t_{30}$, and $\left.t_{60}\right)$. Samples were prepared and homogenized with $2 \mathrm{ml}$ of TCA (1\%) to be later centrifuged at $10,000 \mathrm{G}$ for $5 \mathrm{~min}$. For each sample, the supernatant was mixed with $1 \mathrm{ml}$ of $0.5 \%$ thiobarbituric acid in TCA $(20 \%)$ and then incubated for $30 \mathrm{~min}$ in boiling water. Once cooled to room temperature, the absorbance of each sample was determined at $532 \mathrm{~nm}$ and non-specific absorbance at $600 \mathrm{~nm}$ (Hodges et al., 1999). The MDA content was determined by its molar extinction coefficient of $155 \mathrm{mM}^{-1} \mathrm{~cm}^{-1}$.

\section{Mechanisms of Saline-Stress Tolerance}

To determine the proline accumulation in the foliar tissues of the experimental plants we followed most of the Bate's method (Bates et al., 1973). Samples of fresh healthy leaves ( $250 \mathrm{mg})$ were frozen at each time (i.e., $t_{0}, t_{30}$, and $t_{60}$ ) from the same individuals selected for the TBARS assay. From each individual, a sample of $100 \mathrm{mg}$ was grinded in $1.2 \mathrm{ml}$ of $3 \%$ sulfosalicylic acid. The resulting homogenate was then centrifuged at $16,000 \mathrm{G}$ for $20 \mathrm{~min}$ to obtain $1 \mathrm{ml}$ of the supernatant, which was added to $2 \mathrm{ml}$ of ninhydrin reagent $(2.5 \%$ ninhydrin in glacial acetic acid: distilled water: $85 \%$ orthophosphoric acid [6:3:1]). Each reaction mix was kept for $1 \mathrm{~h}$ in water bath at $90^{\circ} \mathrm{C}$ to develop color. After cooling the test tubes in an ice-bath, $2 \mathrm{ml}$ of toluene was added to separate the chromophores in the sample. Finally, the toluene phase absorbance was read in a spectrophotometer at $525 \mathrm{~nm}$ to further estimate proline concentration by comparing sample absorbances with the standard proline curve.

In addition to the biochemical mechanisms mentioned above, genetic responses of lettuce to saline stress were assessed at each time (i.e., $t_{0}, t_{30}$, and $\left.t_{60}\right)$ through the expression of the NHX1 antiporter gene among a subsample of individuals $(n=$ 5) from each experimental group. To achieve this, total RNA was extracted from foliar samples according to Chang et al. (1993). DNA was removed from aliquots of total RNA using TURBO DNA-free (Applied Biosystems, USA). Synthesis of the cDNA strand was performed according to Ruíz-Carrasco et al. (2011). The quantitative PCR (qPCR) reaction contained the cDNA, $5 \mathrm{pmol}$ of each primer, and $12.5 \mathrm{ml}$ of the Fast SYBR Green PCR master mix (Applied Biosystems. USA). The sequences used to amplify LsNHX1 amplicons ( 200 bp) were: $5^{\prime}$-GCACTTCTGTTGCTGTGAGTTCCA-3' (forward); 5'-TGTGCCCTGACCTCGTAAACTGAT-3' (reverse). PCRs were performed on a Step-One Plus 7500 thermocycler (Applied Biosystems, USA). The process includes an initial cycle of $30 \mathrm{~min}$ at $45^{\circ} \mathrm{C}$ and $2 \mathrm{~min}$ at $95^{\circ} \mathrm{C}$, and then 40 cycles as follows: $95^{\circ} \mathrm{C}$ for $30 \mathrm{~s}, 60^{\circ} \mathrm{C}$ for $30 \mathrm{~s}, 72^{\circ} \mathrm{C}$ for $2 \mathrm{~min}$, and finally one cycle at $72^{\circ} \mathrm{C}$ for $10 \mathrm{~min}$. Cycle threshold (Ct) values were obtained and analyzed with the $2^{-\Delta \Delta C T}$ method (Livak and Schmittgen, 2001). The Elongation Factor 1a (EF1a) housekeeping gene was used as reference gene to normalize, and estimate up- or down-regulation of the target genes for all
qPCR analyses: 5'-GTACGCATGGGTGCTTGACAAACTC$3^{\prime}$ (forward); 5'-ATCAGCCTGGGAGGTACCAGTAAT-3' (reverse). The relative expression ratio $\left(\log _{2}\right)$ between the target gene and EF1a, as well as the fold changes (FC) between controls plants (non-inoculated and without salt stress) and experimentally manipulated individuals were calculated from the qRT-PCR efficiencies and the crossing point deviation using the mathematical model proposed by Pfaffl (2001).

\section{Symbiont Consortium on Crops Productivity}

As a commercial crop, the individual final yield of the monitored lettuce plants was averaged in each experimental group. At the end of the experiment (day 60), all remaining lettuces in the experiment were carefully harvested and their roots gently washed with tap water to separate above (leaves) and belowground (roots) tissues in each individual. After $1 \mathrm{~h}$ of drying in the shade, their respective fresh weights were obtained using a digital scale (Boeco BBL-52; 0.01 g-precision). Finally, total dry biomass was measured after whole lettuce individuals were over-dried at $62^{\circ} \mathrm{C}$ for $96 \mathrm{~h}$ and the constant weight of biomass was achieved.

\section{Statistical Analysis}

To evaluate the effect of symbiont consortium on the average survival percentage in different crops was used a two-way ANOVA with inoculation and salt as independent variables. The effect of microbial inoculation and saline stress on lettuce plants traits was assessed by repeated measures ( $\mathrm{rm}$ ) ANOVAs on the following variables: proline accumulation, lipid peroxidation (TBARS), NHX1 relative gene expression, and photochemical efficiency $\left(\mathrm{F}_{\mathrm{v}} / \mathrm{F}_{\mathrm{m}}\right)$. Non-parametric mixed model fitting was performed with the lme function on the nlme R-package using the individual nested in time as the random error structure (Pinheiro et al., 2017). A posteriori comparisons for the mixed models between experimental groups were performed by the comparison of their Estimated Marginal Means (EMMs), as supported by the pair function in the emmeans R-package (Lenth et al., 2018). Differences in final fresh biomass were analyzed by independent two-way standard ANOVAs for each kind of tissue (root, shoot or the whole plant). We used the presence of the microbial symbionts (inoculated: S+ or non-inoculated: S-) and stress status (no stress: control; saline-stress: stressed) as explanatory variables. When significant results were obtained, a posteriori differences between experimental groups were analyzed by the Honest Significant Differences (HSD) Tukey test (Rohlf and Sokal, 1981).

\section{RESULTS}

\section{Overall Assessment of Symbiont Consortium in Crops}

Average survival was greater in all crop species assessed under control compared with salt-stressed treatment (Figure 1). Similarly, symbiont consortium increase the survival in the majority of crops, with the exception of onion where survival 
TABLE 1 | Repeated measures ANOVA for the effect of saline stress (S) and microbial symbiosis (Sy) on two variables of physiological performance (a: photosynthetic efficiency; b: lipid peroxidation) and two specific stress-response mechanisms (c: proline concentration; $\mathbf{d}$ : $N H X 1$ relative expression).

\begin{tabular}{|c|c|c|c|c|c|}
\hline $\begin{array}{l}\text { Response } \\
\text { variable }\end{array}$ & Source of variation & $d f_{\text {num }}$ & $\boldsymbol{d} \boldsymbol{f}_{\text {den }}$ & $\boldsymbol{F}$ & $p$ \\
\hline \multirow{7}{*}{$\begin{array}{l}\text { Photochemical } \\
\text { efficiency } \\
\text { (Fv/Fm) }\end{array}$} & Stress (S) & 1 & 72 & 908445.8 & $<0.0001$ \\
\hline & Symbiont (Sy) & 1 & 36 & 1226.8 & $<0.0001$ \\
\hline & Time $(\mathrm{T})$ & 1 & 36 & 547.8 & $<0.0001$ \\
\hline & Stress $\times$ Symbiont & 2 & 72 & 366.3 & $<0.0001$ \\
\hline & Stress $\times$ Time & 1 & 36 & 149.1 & $<0.0001$ \\
\hline & Symbiont $\times$ Time & 2 & 72 & 396.4 & $<0.0001$ \\
\hline & $S \times S y \times T$ & 2 & 72 & 165.6 & $<0.0001$ \\
\hline \multirow{7}{*}{$\begin{array}{l}\text { Lipid peroxidation } \\
\text { (TBARS [MDA]) }\end{array}$} & Stress (S) & 1 & 32 & 16724.88 & $<0.0001$ \\
\hline & Symbiont (Sy) & 1 & 16 & 816.535 & $<0.0001$ \\
\hline & Time $(T)$ & 1 & 16 & 382.987 & $<0.0001$ \\
\hline & Stress $\times$ Symbiont & 2 & 32 & 487.53 & $<0.0001$ \\
\hline & Stress $\times$ Time & 1 & 16 & 330.013 & $<0.0001$ \\
\hline & Symbiont $\times$ Time & 2 & 32 & 452.058 & $<0.0001$ \\
\hline & $S \times$ Sy $\times T$ & 2 & 32 & 207.78 & $<0.0001$ \\
\hline \multirow{7}{*}{$\begin{array}{l}\text { Proline } \\
\text { concentration } \\
\text { (mmol/g FW) }\end{array}$} & Stress (S) & 1 & 16 & 901.146 & $<0.0001$ \\
\hline & Symbiont (Sy) & 1 & 16 & 137.093 & $<0.0001$ \\
\hline & Time $(T)$ & 2 & 32 & 185.671 & $<0.0001$ \\
\hline & Stress $\times$ Symbiont & 1 & 16 & 117.031 & $<0.0001$ \\
\hline & Stress $\times$ Time & 2 & 32 & 171.692 & $<0.0001$ \\
\hline & Symbiont $\times$ Time & 2 & 32 & 30.934 & $<0.0001$ \\
\hline & $S \times$ Sy $\times T$ & 2 & 32 & 29.946 & $<0.0001$ \\
\hline \multirow{7}{*}{$\begin{array}{l}\text { NHX1 gene } \\
\text { expression } \\
\text { (Relative fold } \\
\text { change) }\end{array}$} & Stress (S) & 1 & 32 & 513.41 & $<0.0001$ \\
\hline & Symbiont (Sy) & 1 & 16 & 90.69 & $<0.0001$ \\
\hline & Time $(T)$ & 1 & 16 & 1065.19 & $<0.0001$ \\
\hline & Stress $\times$ Symbiont & 2 & 3.2 & 23.23 & 0.0002 \\
\hline & Stress $\times$ Time & 1 & 16 & 755.79 & $<0.0001$ \\
\hline & Symbiont $\times$ Time & 2 & 32 & 92.31 & $<0.0001$ \\
\hline & $\mathrm{S} \times \mathrm{Sy} \times \mathrm{T}$ & 2 & 32 & 31.47 & $<0.0001$ \\
\hline
\end{tabular}

The table shows the probability value (p) obtained for the significance of each factor in the fitted linear mixed model, which was obtained by maximizing the restricted log-likelihood for the data.

percentage in salt-stress treatment was not different between inoculated vs. uninoculated individuals (Figure 1).

Specifically, symbiont consortium significantly increased the survival percentage in cayenne $\operatorname{crop}\left[F_{(1,16)}=30.12 ; p=0.004\right.$; Figure 1A]. Contrarily, salt treatment significantly decreased the survival percentage in cayenne crop $\left[F_{(1,16)}=207.53 ; p<\right.$ $0.0001]$. Interaction between inoculation $\mathrm{x}$ salt was significant $\left[F_{(1,16)}=16.94 ; p=0.008\right]$ since salt treatment decreased the survival with greater intensity in the treatment without symbiont consortium (Figure 1A). In the same way, interaction between inoculation $\mathrm{x}$ salt in lettuce crop was significant $\left[F_{(1,16)}=\right.$ 28.44; $p=0.0067$ ] because the survival average decrease under salt condition, being more evident in uninoculated condition (Figure 1B). On the other hand, onion crop showed a significant decrease in survival under salt-stress condition $\left[F_{(1,16)}=337.50\right.$; $p<0.0001]$, but was not different among inoculated vs. uninoculated condition $\left[F_{(1,16)}=4.17 ; p=0.238\right.$; Figure 1C]. Finally, tomato crop showed a significative interaction between

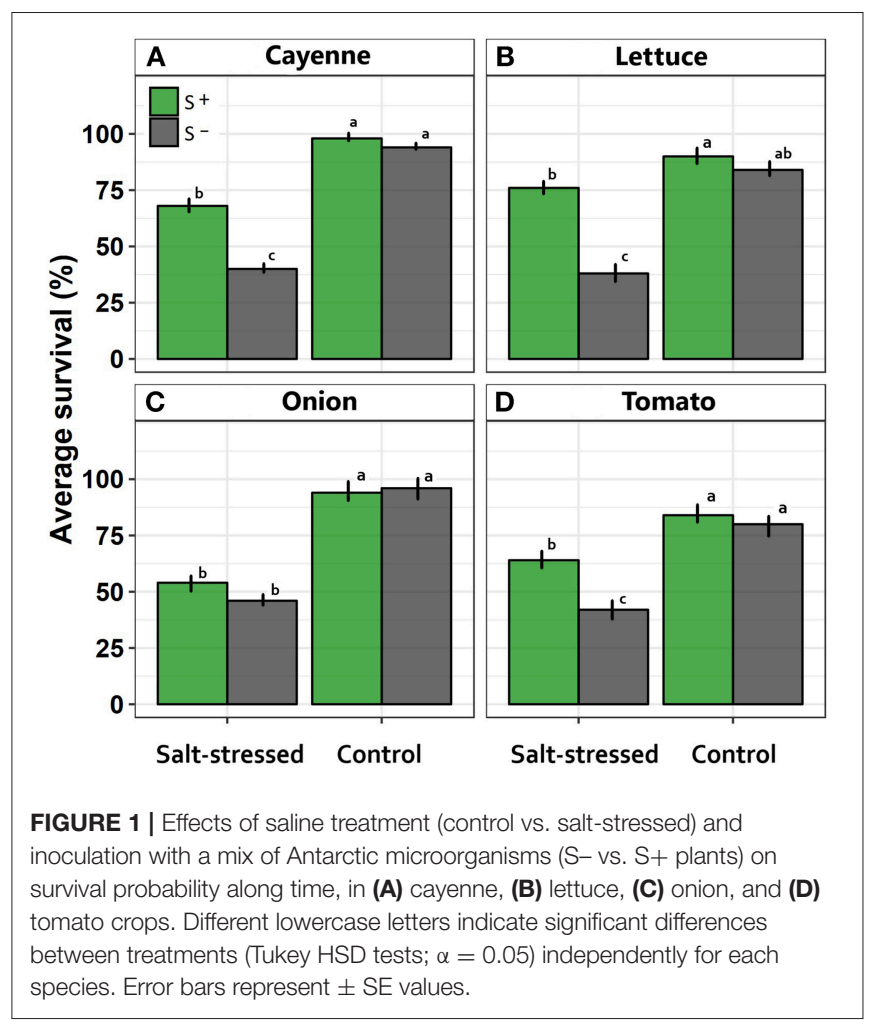

inoculation vs. salt $\left[F_{(1,16)}=9.01 ; p=0.0083\right]$ since those uninoculated individuals showed a more evident decrease in the survival percentage under salt-stress treatment (Figure 1D).

\section{Effects of the Saline-Stress}

Photochemical efficiency, measured as $\mathrm{F}_{\mathrm{v}} / \mathrm{F}_{\mathrm{m}}$, showed the expected trend in plants under saline stress in both $\mathrm{S}_{-}$and $\mathrm{S}+$ individuals, since their photosynthetic performance along time appeared to be negatively affected compared with control individuals without salt addition (Table 1). However, as it could be seen in stressed individuals after 30 and 60 days of saline treatment, the presence of the microbial symbionts significantly ameliorated the negative impact of saline stress. Symbiont appeared to stabilize the decrease of $\mathrm{F}_{\mathrm{v}} / \mathrm{F}_{\mathrm{m}}$ with time (Figure 2A). By contrast, among non-inoculated individuals under salt stress, the values of $\mathrm{F}_{\mathrm{v}} / \mathrm{F}_{\mathrm{m}}$ showed a continuous decrease along time, being the $\mathrm{F}_{\mathrm{v}} / \mathrm{F}_{\mathrm{m}}$ value at end of the experiment significantly lower than those recorded at day 30 (Figure 2A). Interestingly, the symbiotic interaction significantly enhanced the $F_{v} / F_{m}$ values of lettuce plants, even if they were not under saline stress; $\mathrm{S}+$ individuals where already $3.8 \%$ more efficient in their photochemical performance than S- plants by the 30th day, and this difference was maintained in time (Figure 2A). On the other hand, the amount of TBARS showed a substantial increase for both $\mathrm{S}+$ and $\mathrm{S}-$ plants under saline stress. Nevertheless, among $\mathrm{S}+$ individuals, this increase was less than a half of what was observed for their S- counterparts (Figure 2B). Conversely, TBARS concentrations showed no differences at any time in plants without saline stress, despite their symbiotic status (Figure 2B). 

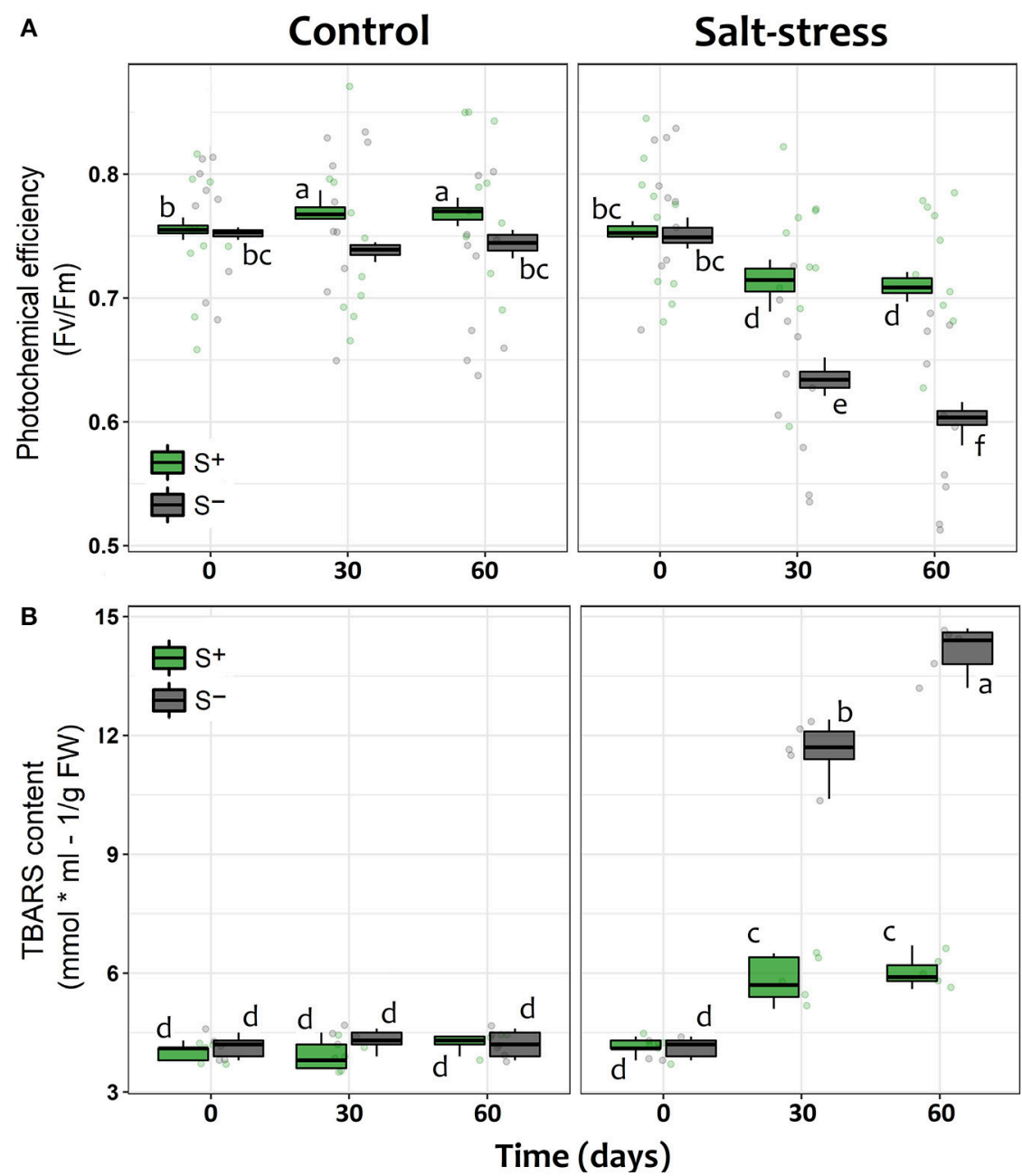

FIGURE 2 | Physiological performance of lettuce individuals measured as (A) the individual photochemical efficiency $\left(F_{v} / F_{m}\right)$ of photosystem II (PSII) and (B) the level of lipid cell membrane peroxidation (TBARS) measured in leaves at 0, 30, and 60 days after exposed to salt stress (200 mM NaCl for "stressed" individuals) and inoculated with the Antarctic microbial consortium (S+ plants). Control groups for both conditions (non-stressed and non-inoculated, S-) are also showed. The box-plot represents the interquartile distribution of the data for each experimental group. Different letters indicate significant a posteriori differences (Tukey test, $\alpha<0.05)$.

\section{Mechanisms of Saline-Stress Tolerance}

The concentration of proline significantly increased after 30 and 60 days in salt-stressed individuals compared to nonstressed plants (Figure 3A). However, whilst S- individuals under saline stress showed an increase in proline concentration of $32 \%$ (day 30) and $48 \%$ (day 60), plants inoculated with the antarctic symbiotic consortium this increase achieved a 96 and $98 \%$, respectively, during the same period (Figure 3A). As expected, among individuals without salt addition the mean proline concentrations were observed to be independent of time and symbiotic interaction (Table $\mathbf{1}$ ). In addition, described as a genetic response to saline-stress (Khan et al., 2013), the relative expression of NHX1 showed larger changes in time among salt-stressed individuals compared with nonstressed S- and S+ plants. Furthermore, under saline stress, major increases appeared to be related with the presence of the symbiotic consortium; at day 30 its increase with respect to the reference value (S- day 0) was $32 \%$ for Sbut $59 \%$ for S+ plants, a difference that was maintained at day 60 (Figure 3B). Interestingly, the symbiotic interaction also changes the NHX1 relative expression under non-stressed conditions, although small (9\%), a significant increase was observed at day 30 among S+ plants. By contrast, the NHX1 expression of $\mathrm{S}$ - individuals do not present changes along time (Figure 3B).

\section{Symbiont Consortium on Crops Productivity}

Overall, those lettuce individuals exposed to salt-stress treatment showed a smaller size than those allocated to control treatment or even those exposed to salt-stress but inoculated with the symbiont consortium (Figure 4). The two-way ANOVA on the final fresh biomass values showed a general negative impact of the saline growth conditions on productivity (factor salt-stress: $d f$ 

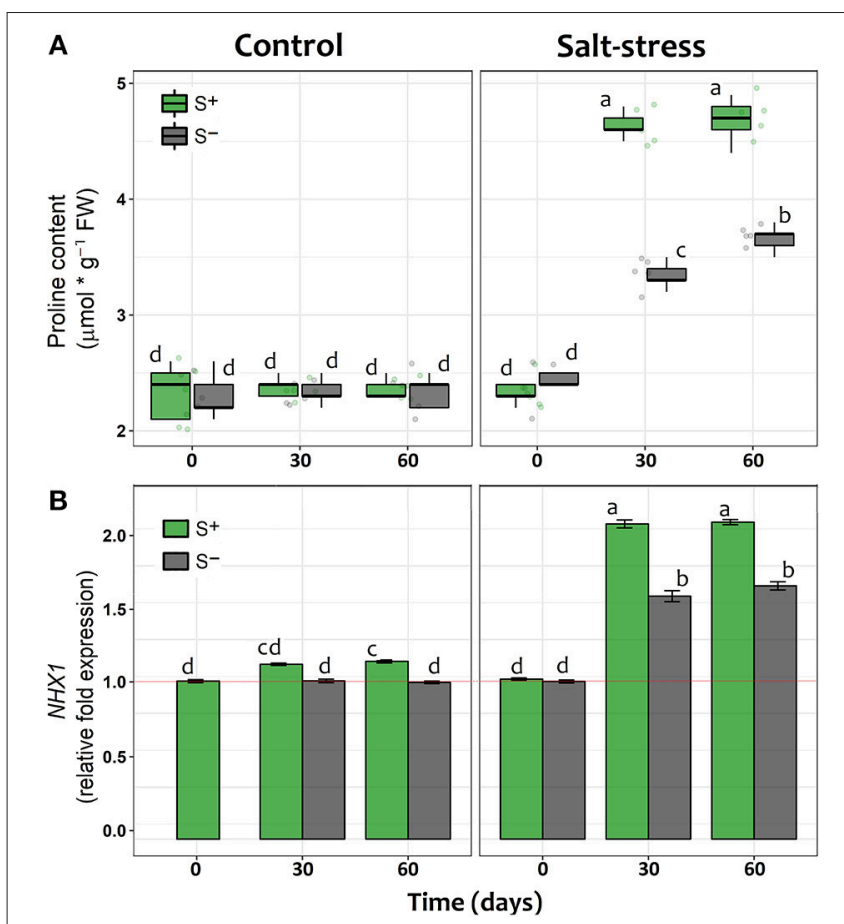

FIGURE 3 | (A, B) Proline concentration (mmol/g FW) and, relative fold gene expression of $N H X 1$ in shoot tissue of lettuce plants measured at 0,30 , and 60 days after exposed to salt stress ( $200 \mathrm{mM} \mathrm{NaCl}$ for "stressed" individuals) and inoculated with the Antarctic microbial consortium (S+ plants). Control groups for both conditions (non-stressed and non-inoculated, S-) are also showed. The relative expression increases are referred to the mean levels of expression in control lettuce plants (i.e., non-stressed and non-inoculated) at time 0 , indicated by a red line. The box-plot represents the interquartile distribution of the data for each experimental group. Error bars at the NHX1 plot represent \pm SE values. Different letters indicate significant a posteriori differences (Tukey test, $\alpha<0.05$ ).

$=1.49 ; F=5.502 ; p=0.023$, Figure 3); however, the significance of the ANOVA interaction term (i.e., inoculation x salt-stress: $d f$ $=1.49 ; F=4.981 ; p=0.031$ ) suggests that this negative effect depends on the symbiotic status. In this sense, the root biomass reduction was only noticed among $\mathrm{S}$ - individuals, as could be observed on the a posteriori HSD-Tukey results (Figure 5). In lettuce plants under salt stress, the absence of microorganisms resulted in a decrease of $38 \%$ in the fresh biomass weight of roots respect to non-stressed plants. The same trend that was observed on the aboveground biomass, with a $31 \%$ mean shoot decrease among S- plants under saline stress and, consequently, on the whole plants (Figure 5). Interestingly, the two-way ANOVA for shoot tissues alone and for the whole individuals, despite shown significant $p$-values for "inoculation" and "salt-stress" as separate terms, do not presented a significant interaction in term of "inoculation x salt-stress" ( hoot: $d f=1.49 ; F=1.777 ; p=0.188$; entire plant: $d f=1,49 ; F=3.047 ; p=0.0871$ ). This suggests a role of both factors in the observed results, however, with an apparent independence between them. Despite this, a-posteriori significant differences on either biomass variables could only be observed between stressed and non-stresses S- plants (Figure 5). By contrast, between both, salt-stressed and non-stressed S+ lettuce plants, we did not find any statistical differences between mean fresh weight of neither root or shoot tissues, nor for the whole plant.

\section{DISCUSSION}

In our study we showed evidence suggesting the importance of symbiont microorganisms from Antarctica improving salt tolerance in crops. In fact, under salt-stress condition the symbiont consortium significantly enhanced the survival in three of four crops assessed here. Hence, selected microorganisms from Antarctic plants could be a successful tool to avoid the negative effect of salt stress to others plant species as crops.

Beyond confirming that Antarctic environments are a fructiferous source of microbial extremophiles with potential applications, the results obtained in this work also unveil part of the mechanisms by which these symbiotic partners could benefit their host-plants. Compared with non-inoculated individuals, an enhanced proline accumulation and increased expression of the NHX1 gene was observed among inoculated lettuces when they were subjected to salt-stress. Additionally, plants that were carrying the symbiotic consortium showed lower levels of cellular damage by lipid peroxidation and higher photosynthetic efficiencies.

Regarding the concentration of osmolytes, as a reported stres S-tolerance mechanism (e.g., glutamate, threalose, peptides, and other $\mathrm{N}$-acetylated amino acids), proline appears to be particularly relevant to reduce the stressful effects of salinity (Hayat et al., 2012; López-Gómez et al., 2014; Reddy et al., 2015; Forni et al., 2017). The derived benefits of proline accumulation for a plant exposed to adverse environmental conditions (i.e., saline soils), could be related with the prevention of electrolyte leakage (Shahid et al., 2014), maintenance of the cell turgor (Ben Ahmed et al., 2011), and/or oxidative burst prevention (Hayat et al., 2012). In our work, the content of proline increased in both inoculated and non-inoculated individuals under salt stress. However, its accumulation in the later appeared to be slower, suggesting a role of the inoculated microorganisms in this process. In this sense, despite it is not possible with our design to differentiate the effects of the fungal and bacterial components of the microbial consortium, the proline-related response observed among inoculated lettuce plants may be originated by rhizobacterial symbionts, as other authors have shown (Kohler et al., 2009; Kumari et al., 2015). According to Creus et al. (2004), the plant-PGPR interaction frequently involves the control of the plant-water dynamics, facilitating the consequent enhanced potential for osmotic adjustment. Thus, it is not surprising that PGPR inoculation has been reported to result in enhanced tolerance to salt stress in several crops (Glick et al., 1997; Mayak et al., 2004; Yildirim and Taylor, 2005; Barassi et al., 2006; Egamberdieva et al., 2013; Forni et al., 2017).

Root-fungal endophytes could also have profound effects on plant performance as they can impact several components of their fitness; for example, by facilitating the uptake of essential nutrients like Potassium, Nitrogen or Phosphorus (Barka et al., 2002; Tanaka et al., 2005). This may have a direct impact in 


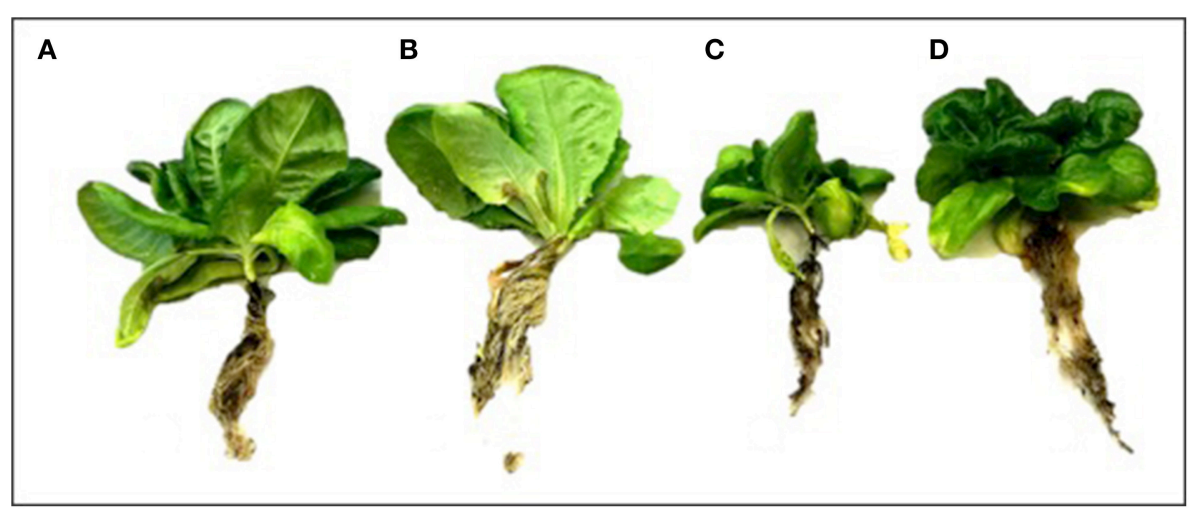

FIGURE 4 | Morphology of lettuce plants after 90 day in each treatment. Uninoculated (S-) plant without salt stress (A); Plants inoculated with a mix of Antarctic microorganisms (S+) not subjected to salt stress (B); S- plants under salt stress (200 mM NaCl) (C); S+ plant under salt stress (200 mM NaCl) (D). Image credit: H. Hansen.

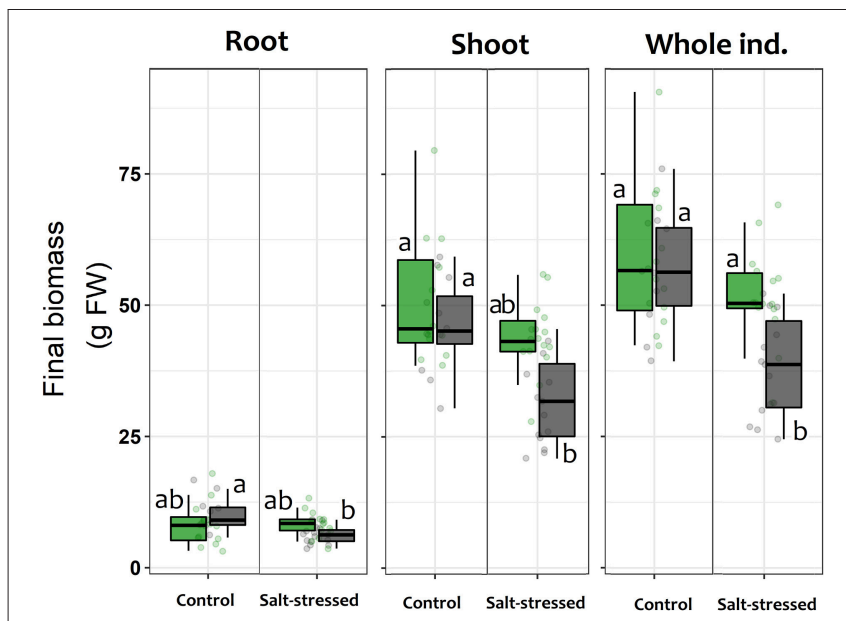

FIGURE 5 | Final mean fresh biomass weight for roots, shoots and whole individuals of lettuce plants after being subjected for 60 days to saline stress ( $200 \mathrm{mM} \mathrm{NaCl}$ for "stressed" individuals) and inoculated with the Antarctic microbial consortium ( $\mathrm{S}+$ plants). Control groups for both conditions (non-stressed and non-inoculated, S-) are also shown. The box-plot represents the interquartile distribution of the data for each experimental group. Different letters indicate significant a posteriori differences (Tukey test, $\alpha<0.05)$.

the physiological processes of the plant that are N-limited like carbon assimilation, and ultimately, growth, especially in soils with low degradation rates of organic matter in the rhizosphere (Jumpponen and Trappe, 1998; Upson et al., 2009). In this regard, diverse enzymes from root-fungal endophytes have been observed to degrade organic molecules like cellulose, lipids, starch, and complex proteins (Petrini et al., 1993; Caldwell et al., 2000; Suryanarayanan et al., 2012). For this reason, it has been proposed that the metabolic activity of these endophytes propitiates the nutritional enhancement of the rhizosphere in which their plant-host is developing (Newsham, 2011).

More similar to the proline response, the augmentation of the NHX1 gene expression observed among inoculated individuals represents a direct effect of the interaction on the response capacity of the host-plant against saline stress. Linked with the synthesis of the NHX antiporter proteins, the expression of the NHX1 gene has been associated with $\mathrm{pH}$ control and $\mathrm{Na}^{+} / \mathrm{K}^{+}$ homeostasis (Leidi et al., 2010; Bassil and Blumwald, 2014), cell expansion (Apse et al., 2003) and salt tolerance (Hernández et al., 2009; Bassil and Blumwald, 2014). A generally accepted mode of operation of this protein is the transport of either $\mathrm{K}^{+}$or $\mathrm{Na}^{+}$into vacuoles in exchange of an $\mathrm{H}^{+}$efflux to the cytosol (Bassil and Blumwald, 2014). These antiporters also contribute to $\mathrm{K}^{+}$uptake which is stored in specific vacuoles for turgor-generation and cell pH regulation (Leidi et al., 2010). This prevents toxic $\mathrm{Na}^{+}: \mathrm{K}^{+}$ ratios in the cytosol while accruing solutes for osmotic balance (McCubbin et al., 2014), for which the vacuolar accumulation of these elements is an especially crucial feature for plants under osmotic stress (Jiang et al., 2010).

For example, the PGPR B. subtilis can also decrease the absorption of excessive amounts of $\mathrm{Na}^{+}$by the roots of plants by down-regulating the expression of the high affinity $\mathrm{K}^{+}$transporter (HKT1) in the roots of salt-affected plants (Zhang et al., 2008; Qin et al., 2016). In addition, the effect of B. subtilis also was related with the shoot-to-root $\mathrm{Na}^{+}$ recirculation by triggering the induction of HKT1 in shoots (Zhang et al., 2008). On the other hand, inoculation with fungal endohytes like Piriformospora indica have also resulted in increases in the expression of NHX1 in salt-grown Arabidopsis compared to non-inoculated individuals (Abdelaziz et al., 2017). In our study, inoculated lettuce plants induced high levels of NHX1 transcripts both under control and salt-stress conditions. However, it is under saline conditions where the relative expression increase appeared to be relevant, reaching almost a two-fold increase in the expression compared with non-inoculated plants.

In conclusion, we could determine that the selected consortium of Antarctic extremophiles effectively reduces the physiological impact of saline stress in a salt-susceptible crop like lettuce, as observed at both the individual and cellular levels. Interestingly, in terms of photochemical efficiency, the 
studied symbiosis leads to increases in plant performance even in the absence of saline stress. Nevertheless, under salinestress, the responses of inoculated lettuce plants largely exceed those of non-inoculated individuals, both in terms of proline concentration and NHX1 relative expression. Furthermore, as a consequence of this enhanced saline-stress tolerance, inoculated plants finalize their productivity cycle with a higher size than their non-inoculated counterparts. This may respond to the higher levels of photosynthetic efficiency sustained over time even under saline conditions, complemented with the decrease in the oxidative effects derived from saline-related ions, which appeared to be controlled by great amounts of NHX antiporters. The role of proline in stabilizing the cellular membranes under salt stress was also evident from the reduced lipid peroxidation measured as TBARS in inoculated plants, which showed almost a three-fold reduction compared with non-inoculated but stressed individuals.

Finally, the use of microorganisms associated with plants from stressful sites appears as a powerful tool for improving salt stress tolerance in intolerant (susceptible) crops. A variety of symbiotic microorganisms are now being used worldwide with the aim of enhancing plant productivity, especially on agricultural crops under saline stress conditions (Kim et al., 2014; Kaushal and Wani, 2016; Orhan, 2016; Qin et al., 2016; Singh and Jha, 2016; Etesami and Beattie, 2018). However, while most studies analyzed the effect of a single symbiotic partner,

\section{REFERENCES}

Abdelaziz, M. E., Kim, D., Ali, S., Fedoroff, N. V., and Al-Babili, S. (2017). The endophytic fungus Piriformospora indica enhances Arabidopsis thaliana growth and modulates $\mathrm{Na}+/ \mathrm{K}+$ homeostasis under salt stress conditions. Plant Sci. 263, 107-115. doi: 10.1016/j.plantsci.2017.07.006

Ahmed, C. B., Magdich, S., Rouina, B. B., Sensoy, S., Boukhris, M., and Abdullah, F. B. (2011). Exogenous proline effects on water relations and ions contents in leaves and roots of young olive. Amino Acids 40, 565-573. doi: 10.1007/s00726-010-0677-1

Alberdi, M., Bravo, L. A., Gutiérrez, A., Gidekel, M., and Corcuera, L. J. (2002). Ecophysiology of Antarctic vascular plants. Physiol. Plant. 115, 479-486. doi: 10.1034/j.1399-3054.2002.1150401.x

Allbed, A., and Kumar, L. (2013). Soil Salinity mapping and monitoring in arid and semi-arid regions using remote sensing technology: a review. Adv. Remote Sens. 2, 373-385. doi: 10.4236/ars.2013.24040

Apse, M. P., Sottosanto, J. B., and Blumwald, E. (2003). Vacuolar cation/H+ exchange, ion homeostasis, and leaf development are altered in a T-DNA insertional mutant of AtNHX1, the Arabidopsis vacuolar $\mathrm{Na}+/ \mathrm{H}+$ antiporter. Plant J. 36, 229-239. doi: 10.1046/j.1365-313X.2003.01871.x

Ashraf, M. P. J. C., and Harris, P. J. C. (2004). Potential biochemical indicators of salinity tolerance in plants. Plant Sci. 166, 3-16. doi: 10.1016/j.plantsci.2003.10.024

Assaha, D. V., Ueda, A., Saneoka, H., Al-Yahyai, R., and Yaish, M. W. (2017). The role of $\mathrm{Na}+$ and $\mathrm{K}+$ transporters in salt stress adaptation in glycophytes. Front. Physiol. 8:509. doi: 10.3389/fphys.2017.00509

Barassi, C. A., Ayrault, G., Creus, C. M., Sueldo, R. J., and Sobrero, M. T. (2006). Seed inoculation with Azospirillum mitigates $\mathrm{NaCl}$ effects on lettuce. Sci. Hortic. 109, 8-14. doi: 10.1016/j.scienta.2006.02.025

Barka, E. A., Gognies, S., Nowak, J., Audran, J. C., and Belarbi, A. (2002). Inhibitory effect of endophyte bacteria on Botrytis cinerea and its influence to promote the grapevine growth. Biol. Control 24, 135-142. doi: 10.1016/S1049-9644(02)00034-8 the high diversity of occurring microorganisms also implies a wide spectrum of physiological and biochemical effects. In this sense, while it is expected that we should aim to fully understand the nature of each plant-microbe relation, broad benefits for a potential plant-host could arise from the "consortium" approach to its symbiotic interactions (Sturz and Nowak, 2000; Faust, 2019).

\section{AUTHOR CONTRIBUTIONS}

MM-M, IA-R, and HH designed the experiments. MM-M, JG-C, and $\mathrm{HH}$ performed the experiments. MM-M, IA-R, $\mathrm{HH}$, and CA analyzed the data. IA-R and MM-M wrote the paper along with $\mathrm{HH}$, JG-C, and CA. All authors reviewed the manuscript.

\section{FUNDING}

MM-M was funded by FONDECYT regular 1181034.

\section{ACKNOWLEDGMENTS}

We thank Instituto Antártico Chileno (INACH) and the Chilean Navy for logistics and field support. All sampling was performed in accordance to international permits and authorizations given by INACH. MM-M thanks to Milko Jorquera for the invitation to participate of this special issue.

Bassil, E., and Blumwald, E. (2014). The ins and outs of intracellular ion homeostasis: NHX-type cation/H+ transporters. Curr. Opin. Plant Biol. 22, 1-6. doi: 10.1016/j.pbi.2014.08.002

Bates, L. S., Waldren, R. P., and Teare, I. D. (1973). Rapid determination of free proline for water-stress studies. Plant Soil 39, 205-207. doi: 10.1007/BF00018060

Bianco, C., and Defez, R. (2009). Medicago truncatula improves salt tolerance when modulated by an indole-3-acetic acid-overproducing Sinorhizobium meliloti strain. J. Exp. Bot. 60, 3097-3107. doi: 10.1093/jxb/e rp140

Caldwell, B. A., Jumpponen, A., and Trappe, J. M. (2000). Utilization of major detrital substrates by dark-septate, root endophytes. Mycologia 92, 230-232. doi: $10.2307 / 3761555$

Chang, S., Puryear, J., and Cairney, J. (1993). A simple and efficient method for isolating RNA from pine trees. Plant Mol. Biol. Rep. 11, 113-116. doi: $10.1007 / \mathrm{BF} 02670468$

Cocking, E. C. (2003). Endophytic colonization of plant roots by nitrogen-fixing bacteria. Plant Soil 252, 169-175. doi: 10.1023/A:1024106605806

Coleman-Derr, D., and Tringe, S. G. (2014). Building the crops of tomorrow: advantages of symbiont-based approaches to improving abiotic stress tolerance. Front. Microbiol. 5:283. doi: 10.3389/fmicb.2014.00283

Convey, P., Gibson, J. A., Hillenbrand, C. D., Hodgson, D. A., Pugh, P. J., Smellie, J. L., et al. (2008). Antarctic terrestrial life-challenging the history of the frozen continent? Biol. Rev. 83, 103-117. doi: 10.1111/j.1469-185X.2008.00034.x

Creus, C. M., Sueldo, R. J., and Barassi, C. A. (2004). Water relations and yield in Azospirillum-inoculated wheat exposed to drought in the field. Can. J. Bot. 82, 273-281. doi: 10.1139/b03-119

Dodd, I. C., and Pérez-Alfocea, F. (2012). Microbial amelioration of crop salinity stress. J. Exp. Bot. 63, 3415-3428. doi: 10.1093/jxb/ers033

Egamberdieva, D., Berg, G., Lindström, K., and Räsänen, L. A. (2013). Alleviation of salt stress of symbiotic Galega officinalis L. (goat's rue) by co-inoculation of Rhizobium with root-colonizing Pseudomonas. Plant Soil 369, 453-465. doi: $10.1007 / \mathrm{s} 11104-013-1586-3$ 
Egert, M., and Tevini, M. (2002). Influence of drought on some physiological parameters symptomatic for oxidative stress in leaves of chives (Allium schoenoprasum). Environ. Exp. Bot. 48, 43-49. doi: 10.1016/S0098-8472(02)00008-4

Etesami, H., and Beattie, G. A. (2018). Mining halophytes for plant growthpromoting halotolerant bacteria to enhance the salinity tolerance of nonhalophytic crops. Front. Microbiol. 9:148. doi: 10.3389/fmicb.2018.00148

Fardella, C., Oses, R., Torres-Díaz, C., and Molina-Montenegro, M. A. (2014). Antarctic fungal endophytes as tool for the reintroduction of native plant species in arid zones. Bosque 35, 235-239. doi: $10.4067 /$ S0717-92002014000200011

Faust, K. (2019). Microbial consortium design benefits from metabolic modeling. Trends Biotechnol. 37, 123-125. doi: 10.1016/j.tibtech.2018.11.004

Food and Agriculture Organization of the United Nations (2009). State of Food Insecurity in the World 2009. Rome: FAO.

Forni, C., Duca, D., and Glick, B. R. (2017). Mechanisms of plant response to salt and drought stress and their alterations by rhizobacteria. Plant Soil 410, 335-356. doi: 10.1007/s11104-016-3007-x

Gallardo-Cerda, J., Levihuan, J., Lavín, P., Oses, R., Atala, C., Torres-Díaz, C., et al. (2018). Antarctic rhizobacteria improve salt tolerance and physiological performance of the Antarctic vascular plants. Polar Biol. 41, 1973-1982. doi: $10.1007 / \mathrm{s} 00300-018-2336-z$

Glenn, E. P., Brown, J. J., and Blumwald, E. (1999). Salt tolerance and crop potential of halophytes. Crit. Rev. Plant Sci. 18, 227-255. doi: $10.1080 / 07352689991309207$

Glick, B. R., Liu, C., Ghosh, S., and Dumbroff, E. B. (1997). Early development of canola seedlings in the presence of the plant growthpromoting rhizobacterium Pseudomonas putida GR12-2. Soil Biol. Biochem. 29, 1233-1239. doi: 10.1016/S0038-0717(97)00026-6

Godfray, H. C. J., Beddington, J. R., Crute, I. R., Haddad, L., Lawrence, D., Muir, J. F., et al. (2010). Food security: the challenge of feeding 9 billion people. Science 327, 812-818. doi: 10.1126/science. 1185383

Greenfield, M., Gómez-Jiménez, M. I., Ortiz, V., Vega, F. E., Kramer, M., and Parsa, S. (2016). Beauveria bassiana and Metarhizium anisopliae endophytically colonize cassava roots following soil drench inoculation. Biol. Control 95, 40-48. doi: 10.1016/j.biocontrol.2016.01.002

Hadi, F., Bano, A., and Fuller, M. P. (2010). The improved phytoextraction of lead $(\mathrm{Pb})$ and the growth of maize (Zea mays L.): the role of plant growth regulators (GA3 and IAA) and EDTA alone and in combinations. Chemosphere 80, 457-462. doi: 10.1016/j.chemosphere.2010.04.020

Hayat, S., Hayat, Q., Alyemeni, M. N., Wani, A. S., Pichtel, J., and Ahmad, A. (2012). Role of proline under changing environments: a review. Plant Signal. Behav. 7, 1456-1466. doi: 10.4161/psb.21949

Hernández, A., Jiang, X., Cubero, B., Nieto, P. M., Bressan, R. A., Hasegawa, P. M., et al. (2009). Mutants of the Arabidopsis thaliana cation/H+ antiporter AtNHX1 conferring increased salt tolerance in yeast. The endosome/prevacuolar compartment is a target for salt toxicity. J. Biol. Chem. 284, 14276-14285. doi: 10.1074/jbc.M806203200

Hodges, D. M., DeLong, J. M., Forney, C. F., and Prange, R. K. (1999). Improving the thiobarbituric acid-reactive-substances assay for estimating lipid peroxidation in plant tissues containing anthocyanin and other interfering compounds. Planta 207, 604-611. doi: 10.1007/s004250050524

Jiang, X., Leidi, E. O., and Pardo, J. M. (2010). How do vacuolar NHX exchangers function in plant salt tolerance? Plant Signal. Behav. 5, 792-795. doi: $10.4161 /$ psb.5.7.11767

Joshi, R., Mangu, V. R., Bedre, R., Sanchez, L., Pilcher, W., Zandkarimi, H., et al. (2015). "Salt adaptation mechanisms of halophytes: improvement of salt tolerance in crop plants" in Elucidation of Abiotic Stress Signaling in Plants, ed K. P. Girdhar (New York, NY: Springer), 243-279.

Jumpponen, A. R. I., and Trappe, J. M. (1998). Dark septate endophytes: a review of facultative biotrophic root-colonizing fungi. N. Phytol. 140, 295-310. doi: 10.1046/j.1469-8137.1998.00265.x

Kang, S. M., Radhakrishnan, R., Khan, A. L., Kim, M. J., Park, J. M., Kim, B. R., et al. (2014). Gibberellin secreting rhizobacterium, Pseudomonas putida $\mathrm{H}-2-$ 3 modulates the hormonal and stress physiology of soybean to improve the plant growth under saline and drought conditions. Plant Physiol. Biochem. 84, 115-124. doi: 10.1016/j.plaphy.2014.09.001
Kang, S. M., Radhakrishnan, R., You, Y. H., Khan, A. L., Park, J. M., Lee, S. M., et al. (2015). Cucumber performance is improved by inoculation with plant growth-promoting microorganisms. Acta Agric. Scand. 65, 36-44. doi: 10.1080/09064710.2014.960889

Karlidag, H., Yildirim, E., Turan, M., Pehluvan, M., and Donmez, F. (2013). Plant growth-promoting rhizobacteria mitigate deleterious effects of salt stress on strawberry plants (Fragaria $\times$ ananassa). Hortscience 48, 563-567. doi: 10.21273/HORTSCI.48.5.563

Kaushal, M., and Wani, S. P. (2016). Rhizobacterial-plant interactions: strategies ensuring plant growth promotion under drought and salinity stress. Agric. Ecosyst. Environ. 231, 68-78. doi: 10.1016/j.agee.2016.06.031

Khan, A. L., Waqas, M., Khan, A. R., Hussain, J., Kang, S. M., Gilani, S. A., et al. (2013). Fungal endophyte Penicillium janthinellum LK5 improves growth of ABA-deficient tomato under salinity. World J. Microbiol. Biotechnol. 29, 2133-2144. doi: 10.1007/s11274-013-1378-1

Kim, K., Jang, Y. J., Lee, S. M., Oh, B. T., Chae, J. C., and Lee, K. J. (2014). Alleviation of salt stress by Enterobacter sp. EJ01 in tomato and Arabidopsis is accompanied by up-regulation of conserved salinity responsive factors in plants. Mol. Cells 37:109. doi: 10.14348/molcells.2014.2239

Kohler, J., Hernández, J. A., Caravaca, F., and Roldán, A. (2009). Induction of antioxidant enzymes is involved in the greater effectiveness of a PGPR versus AM fungi with respect to increasing the tolerance of lettuce to severe salt stress. Environ. Exp. Bot. 65, 245-252. doi: 10.1016/j.envexpbot.2008.09.008

Krishna, G., Singh, B. K., Kim, E. K., Morya, V. K., and Ramteke, P. W. (2015). Progress in genetic engineering of peanut (Arachis hypogaea L.)-A review. Plant Biotechnol. J. 13, 147-162. doi: 10.1111/pbi.12339

Kumari, S., Vaishnav, A., Jain, S., Varma, A., and Choudhary, D. K. (2015) Bacterial-mediated induction of systemic tolerance to salinity with expression of stress alleviating enzymes in soybean (Glycine max L. Merrill). J. Plant Growth Regul. 34, 558-573. doi: 10.1007/s00344-015-9490-0

Leidi, E. O., Barragán, V., Rubio, L., El-Hamdaoui, A., Ruiz, M. T., Cubero, B., et al. (2010). The AtNHX1 exchanger mediates potassium compartmentation in vacuoles of transgenic tomato. Plant J. 61, 495-506. doi: 10.1111/j.1365-313X.2009.04073.x

Lenth, R., Love, J., and Hervé, M. (2018). 'emmeans': Estimated Marginal Means, aka Least-Squares Means. R-package, version 1.2.2. Available online at: https:// CRAN.R-project.org/package $=$ emmeans

Livak, K. J., and Schmittgen, T. D. (2001). Analysis of relative gene expression data using real-time quantitative PCR and the 2- $\Delta \Delta \mathrm{CT}$ method. Methods 25, 402-408. doi: 10.1006/meth.2001.1262

López-Gómez, M., Hidalgo-Castellanos, J., Iribarne, C., and Lluch, C. (2014). Proline accumulation has prevalence over polyamines in nodules of Medicago sativa in symbiosis with Sinorhizobium meliloti during the initial response to salinity. Plant Soil 374, 149-159. doi: 10.1007/s11104-013 $-1871-1$

Maxwell, K., and Johnson, G. N. (2000). Chlorophyll fluorescence a practical guide. J. Exp. Bot. 51, 659-668. doi: 10.1093/jexbot $/ 51.3$ 45.659

Mayak, S., Tirosh, T., and Glick, B. R. (2004). Plant growth-promoting bacteria confer resistance in tomato plants to salt stress. Plant Physiol. Biochem. 42, 565-572. doi: 10.1016/j.plaphy.2004.05.009

McCubbin, T., Bassil, E., Zhang, S., and Blumwald, E. (2014). Vacuolar Na+/H+ NHX-type antiporters are required for cellular $\mathrm{K}+$ homeostasis, microtubule organization and directional root growth. Plants 3, 409-426. doi: 10.3390/plants3030409

Molina-Montenegro, M. A., Oses, R., Torres-Díaz, C., Atala, C., Zurita-Silva, A., and Ruiz-Lara, S. (2016). Root-endophytes improve the ecophysiological performance and production of an agricultural species under drought condition. AoB Plants 8:plw062. doi: 10.1093/aobpla/plw062

Molina-Montenegro, M. A., Salgado-Luarte, C., Oses, R., and TorresDíaz, C. (2013). Is physiological performance a good predictor for fitness? Insights from an invasive plant species. PLOS ONE 8:e76432. doi: 10.1371/journal.pone.0076432

Molina-Montenegro, M. A., Zurita-Silva, A., and Oses, R. (2011). Effect of water availability on physiological performance and lettuce crop yield (Lactuca sativa). Ciencia e Investigación Agraria 38, 65-74. doi: 10.4067/S0718-16202011000100006 
Munns, R. (1993). Physiological processes limiting plant growth in saline soils: some dogmas and hypotheses. Plant Cell Environ. 16, 15-24. doi: 10.1111/j.1365-3040.1993.tb00840.x

Munns, R., and James, R. A. (2003). Screening methods for salinity tolerance: a case study with tetraploid wheat. Plant Soil 253, 201-218. doi: 10.1023/A:1024553303144

Munns, R., and Tester, M. (2008). Mechanisms of salinity tolerance. Аnnu. Rev. Plant Biol. 59, 651-681. doi: 10.1146/annurev.arplant.59.032607.0 92911

Newsham, K. K. (2011). A meta-analysis of plant responses to dark septate root endophytes. N. Phytol. 190, 783-793. doi: 10.1111/j.1469-8137.2010. 03611.x

Nissen, J., and San martín, K. (2004). Uso de poliacrilamidas y el riego en el manejo hídrico de lechugas (Lactuca sativa L.). Agro Sur. 32, 1-12. doi: 10.4206/agrosur.2004.v32n2-01

Orhan, F. (2016). Alleviation of salt stress by halotolerant and halophilic plant growth-promoting bacteria in wheat (Triticum aestivum). Braz. J. Microbiol. 47, 621-627. doi: 10.1016/j.bjm.2016.04.001

Pandey, G. K., Kanwar, P., Singh, A., Steinhorst, L., Pandey, A., Yadav, A. K., et al. (2015). CBL-interacting protein kinase, CIPK21, regulates osmotic and salt stress responses in Arabidopsis. Plant Physiol. 169, 780-792. doi: $10.1104 /$ pp. 15.00623

Parnikoza, I., Kozeretska, I., and Kunakh, V. (2011). Vascular plants of the Maritime Antarctic: origin and adaptation. Am. J. Plant Sci. 2, 381-395. doi: 10.4236/ajps.2011.23044

Paul, D., and Lade, H. (2014). Plant-growth-promoting rhizobacteria to improve crop growth in saline soils: a review. Agron. Sustain. Dev. 34, 737-752. doi: 10.1007/s13593-014-0233-6

Petrini, O., Sieber, T. N., Toti, L., and Viret, O. (1993). Ecology, metabolite production, and substrate utilization in endophytic fungi. Nat. Toxins 1, 185-196. doi: 10.1002/nt.2620010306

Pfaffl, M. W. (2001). A new mathematical model for relative quantification in real-time RT-PCR. Nucleic Acids Res. 29, e45-e45. doi: 10.1093/nar/29. 9.e45

Pinheiro, J., Bates, D., DebRoy, S., Sarkar, D., Heisterkamp, S., Van Willigen, B., et al. (2017). 'nlme': Linear and Nonlinear Mixed Effects Models. R-package version 3.1. Available online at: https://cran.r-project.org/web/packages/nlme/ nlme.pdf

Qin, Y., Druzhinina, I. S., Pan, X., and Yuan, Z. (2016). Microbially mediated plant salt tolerance and microbiome-based solutions for saline agriculture. Biotechnol. Adv. 34, 1245-1259. doi: 10.1016/j.biotechadv.2016. 08.005

Radhakrishnan, R., Khan, A. L., Kang, S. M., and Lee, I. J. (2015). A comparative study of phosphate solubilization and the host plant growth promotion ability of Fusarium verticillioides RK01 and Humicola sp. KNU01 under salt stress. Ann. Microbiol. 65, 585-593. doi: 10.1007/s13213-014-0894-z

Ramos, P., Rivas, N., Pollmann, S., Casati, P., and Molina-Montenegro, M. A. (2018). Hormonal and physiological changes driven by fungal endophytes increase Antarctic plant performance under UV-B radiation. Fungal Ecol. 34, 76-82. doi: 10.1016/j.funeco.2018.05.006

Reddy, P. S., Jogeswar, G., Rasineni, G. K., Maheswari, M., Reddy, A. R., Varshney, R. K., et al. (2015). Proline over-accumulation alleviates salt stress and protects photosynthetic and antioxidant enzyme activities in transgenic sorghum [Sorghum bicolor (L.) Moench]. Plant Physiol. Biochem. 94, 104-113. doi: 10.1016/j.plaphy.2015.05.014

Redman, R. S., Kim, Y. O., Woodward, C. J., Greer, C., Espino, L., Doty, S. L., et al. (2011). Increased fitness of rice plants to abiotic stress via habitat adapted symbiosis: a strategy for mitigating impacts of climate change. PLoS ONE 6:e14823. doi: 10.1371/journal.pone.0014823

Rho, H., Hsieh, M., Kandel, S. L., Cantillo, J., Doty, S. L., and Kim, S. H. (2017). Do endophytes promote growth of host plants under stress? A metaanalysis on plant stress mitigation by endophytes. Microb. Ecol. 75, 407-418. doi: $10.1007 / \mathrm{s} 00248-017-1054-3$

Rohlf, F. J., and Sokal, R. R. (1981). Biometry: The Principles and Practice of Statistics in Biological Research. New York, NY: WH Freeman.

Rozema, J., and Flowers, T. (2008). Crops for a salinized world. Science 322, 1478-1480. doi: $10.1126 /$ science.1168572
Ruíz-Carrasco, K., Antognoni, F., Coulibaly, A. K., Lizardi, S., Covarrubias, A., Martínez, E. A., et al. (2011). Variation in salinity tolerance of four lowland genotypes of quinoa (Chenopodium quinoa Willd.) as assessed by growth, physiological traits, and sodium transporter gene expression. Plant Physiol. Biochem. 49, 1333-1341. doi: 10.1016/j.plaphy.2011.08.005

Saha, J., Brauer, E. K., Sengupta, A., Popescu, S. C., Gupta, K., and Gupta, B. (2015). Polyamines as redox homeostasis regulators during salt stress in plants. Front. Environ. Sci. 3:21. doi: 10.3389/fenvs.2015.00021

Saikkonen, K., Faeth, S. H., Helander, M., and Sullivan, T. J. (1998). Fungal endophytes: a continuum of interactions with host plants. Annu. Rev. Ecol. Systemat. 29, 319-343. doi: 10.1146/annurev.ecolsys.29.1.319

Sánchez, C. H. A. (2000). Response of lettuce to water and nitrogen on sand and the potential for leaching of nitrate-N. Hortic. Sci. 35, 73-75. doi: 10.21273/HORTSCI.35.1.73

Santiago, I. F., Rosa, C. A., and Rosa, L. H. (2017). Endophytic symbiont yeasts associated with the Antarctic angiosperms Deschampsia antarctica and Colobanthus quitensis. Polar Biol. 40, 177-183. doi: 10.1007/s00300-016-1940-z

Shahid, M. A., Balal, R. M., Pervez, M. A., Abbas, T., Aqeel, M. A., Javaid, M. M., et al. (2014). Exogenous proline and proline-enriched Lolium perenne leaf extract protects against phytotoxic effects of nickel and salinity in Pisum sativum by altering polyamine metabolism in leaves. Turk. J. Bot. 38, 914-926. doi: 10.3906/bot-1312-13

Singh, R. P., and Jha, P. N. (2016). The multifarious PGPR Serratia marcescens CDP-13 augments induced systemic resistance and enhanced salinity tolerance of wheat (Triticum aestivum L.). PLOS ONE 11:e0155026. doi: 10.1371/journal.pone. 0155026

Sturz, A. V., and Nowak, J. (2000). Endophytic communities of rhizobacteria and the strategies required to create yield enhancing associations with crops. Appl. Soil Ecol. 15, 183-190. doi: 10.1016/S0929-1393(00)0 0094-9

Sun, M. H., Ma, Q. J., Liu, X., Zhu, X. P., Hu, D. G., and Hao, Y. J. (2017). Molecular cloning and functional characterization of MdNHX1 reveals its involvement in salt tolerance in apple calli and Arabidopsis. Sci. Hortic. 215, 126-133. doi: $10.1016 /$ j.scienta.2016.11.031

Suryanarayanan, T. S., Thirunavukkarasu, N., Govindarajulu, M. B., and Gopalan, V. (2012). Fungal endophytes: an untapped source of biocatalysts. Fungal Divers. 54, 19-30. doi: 10.1007/s13225-0120168-7

Szabados, L., and Savoure, A. (2010). Proline: a multifunctional amino acid. Trends Plant Sci. 15, 89-97. doi: 10.1016/j.tplants.2009.11.009

Székely, G., Ábrahám, E., Csépl,o, Á., Rigó, G., Zsigmond, L., Csiszár, J., et al. (2008). Duplicated P5CS genes of Arabidopsis play distinct roles in stress regulation and developmental control of proline biosynthesis. Plant J. 53, 11-28. doi: 10.1111/j.1365-313X.2007.03318.x

Tanaka, A., Tapper, B. A., Popay, A., Parker, E. J., and Scott, B. (2005). A symbiosis expressed non-ribosomal peptide synthetase from a mutualistic fungal endophyte of perennial ryegrass confers protection to the symbiotum from insect herbivory. Mol. Microbiol. 57, 1036-1050. doi: $10.1111 / j .1365-2958.2005 .04747 . x$

Tester, M., and Davenport, R. (2003). Na+ tolerance and $\mathrm{Na}+$ transport in higher plants. Ann. Bot. 91, 503-527. doi: 10.1093/aob/mcg058

Torres-Díaz, C., Gallardo-Cerda, J., Lavin, P., Oses, R., Carrasco-Urra, F., Atala, C., et al. (2016). Biological interactions and simulated climate change modulates the ecophysiological performance of Colobanthus quitensis in the Antarctic ecosystem. PLoS ONE 11:e0164844. doi: 10.1371/journal.pone.0 164844

Upson, R., Read, D. J., and Newsham, K. K. (2009). Nitrogen form influences the response of Deschampsia antarctica to dark septate root endophytes. Mycorrhiza 20, 1-11. doi: 10.1007/s00572-0090260-3

Vandenkoornhuyse, P., Quaiser, A., Duhamel, M., Le Van, A., and Dufresne, A. (2015). The importance of the microbiome of the plant holobiont. N. Phytol. 206, 1196-1206. doi: 10.1111/nph.13312

Yildirim, E., and Taylor, A. G. (2005). Effect of biological treatments on growth of bean plants under salt stress. Annu. Rep. Been Improvement Cooperat. 48, 176-177. Available online at: http://arsftfbean.uprm.edu/bic/wp-content/ uploads/2018/05/BIC_2005_volume_48.pdf 
Zhang, H., Kim, M. S., Sun, Y., Dowd, S. E., Shi, H., and Paré, P. W. (2008). Soil bacteria confer plant salt tolerance by tissue-specific regulation of the sodium transporter HKT1. Mol. Plant Microbe Interact. 21, 737-744. doi: 10.1094/MPMI-21-6-0737

Zheng, Y. H., Xu, X. B., Wang, M. Y., Zheng, X. H., Li, Z. J., and Jiang, G. M. (2009). Responses of salt-tolerant and intolerant wheat genotypes to sodium chloride: photosynthesis, antioxidants activities, and yield. Photosynthetica 47, 87-94. doi: 10.1007/s11099-0090014-7

Zhu, J. K. (2001). Plant salt tolerance. Trends Plant Sci. 6, 66-71. doi: 10.1016/S1360-1385(00)01838-0
Conflict of Interest Statement: The authors declare that the research was conducted in the absence of any commercial or financial relationships that could be construed as a potential conflict of interest.

Copyright (C) 2019 Acuña-Rodríguez, Hansen, Gallardo-Cerda, Atala and MolinaMontenegro. This is an open-access article distributed under the terms of the Creative Commons Attribution License (CC BY). The use, distribution or reproduction in other forums is permitted, provided the original author(s) and the copyright owner(s) are credited and that the original publication in this journal is cited, in accordance with accepted academic practice. No use, distribution or reproduction is permitted which does not comply with these terms. 